\title{
Would you rather be a 'birth' or a 'genetic' mother? If so, how much?
}

\author{
J G Thornton, H M McNamara and I A Montague Institute of Epidemiology and Health Services Research, \\ Leeds University, Leeds
}

\begin{abstract}
Authors' abstract
fudges face difficult choices when the birth and genetic mothers of a child are separate people who dispute maternal access; the views of the general population may help them. Fifty women were asked whether, if they were infertile and could have only one child, they would prefer to be birth mothers (to carry a baby which was not genetically theirs) or genetic mothers (to have another woman carry their genetic baby). Similarly, fifty men were asked about their preference for a partner's child. In both groups the strength of preferences was measured using a lottery technique. The direction and strength of preferences was similar between men and women, and approximately equally divided between birth and genetic motherhood. These attitudes should be taken into account by those adjudicating custody disputes between such mothers.
\end{abstract}

\section{Introduction}

To become a mother, a woman normally has both to provide an ovum, and to house the conceptus until delivery. By using extracorporeal fertilization of donated ova as treatment for women without ovaries, and full surrogacy for women without a uterus, these functions are separated. The resulting baby has two mothers, a 'genetic mother' who provided the ovum, and a 'birth mother' who carried the pregnancy to term.

In a recent Californian court case (1) the custody of a child conceived by surrogacy was disputed. The commissioning woman, Crispina Calvert, had had a hysterectomy, making her unable to bear a child. She and her husband Mark paid a surrogate, Anna Johnson, $\$ 10,000$ to carry a pregnancy conceived from Crispina's ovum and Mark's sperm, and to surrender the child at birth. At the end of the pregnancy Anna Johnson sought a court ruling that she was the child's legal mother and requested visiting rights. She claimed that she had become emotionally bonded to the child. However, the lower court ruled that Crispina Calvert alone should be considered the child's legal mother and that Anna Johnson's relationship was analogous to that of a foster parent who had looked after the child for nine months. This decision was upheld at appeal (2) where the judges decided that genes determine maternity and gave no weight at all to birth motherhood. Although the validity of the contract and the best interests of the child were used by the lower court judge to support his decision, these issues were not considered relevant by the appeal court. This decision has been criticised (3) and runs counter to the guidelines of the American College of Obstetricians and Gynecologists (4). If supported by courts elsewhere it would put ovum donation in jeopardy since the ovum donor would be regarded as the legal mother rather than the recipient mother.

This case stimulated us to measure the relative importance of birth and genetic motherhood to the general population. Since men and women may differ in their views on this matter, we studied them separately. The results of such enquiries might help judges, since if two individuals both claim to be emotionally bonded to a child, it is difficult during a dispute directly to measure the strength of their attachment. However, we can ask a sample of other individuals how strongly they would anticipate being bonded to the child in similar hypothetical situations. One method to measure strength of preference is that used in classical decision analysis to measure individuals' utilities. Subjects are asked at what lottery between a favoured and an unfavoured outcome they would be indifferent whether they received a certain intermediate outcome. If the utility of the unfavoured outcome is set at zero and that of the favoured outcome at one, the probability $(p)$ of the favoured outcome defines the utility of the intermediate outcome (5). The results of such a study would have moral significance for decision-makers who wish to act according to the 'golden rule' and treat others as they would wish to be treated themselves.

\section{Methods}

Two convenience samples were selected. The first consisted of 50 women aged between 19 and 42

\section{Key words}




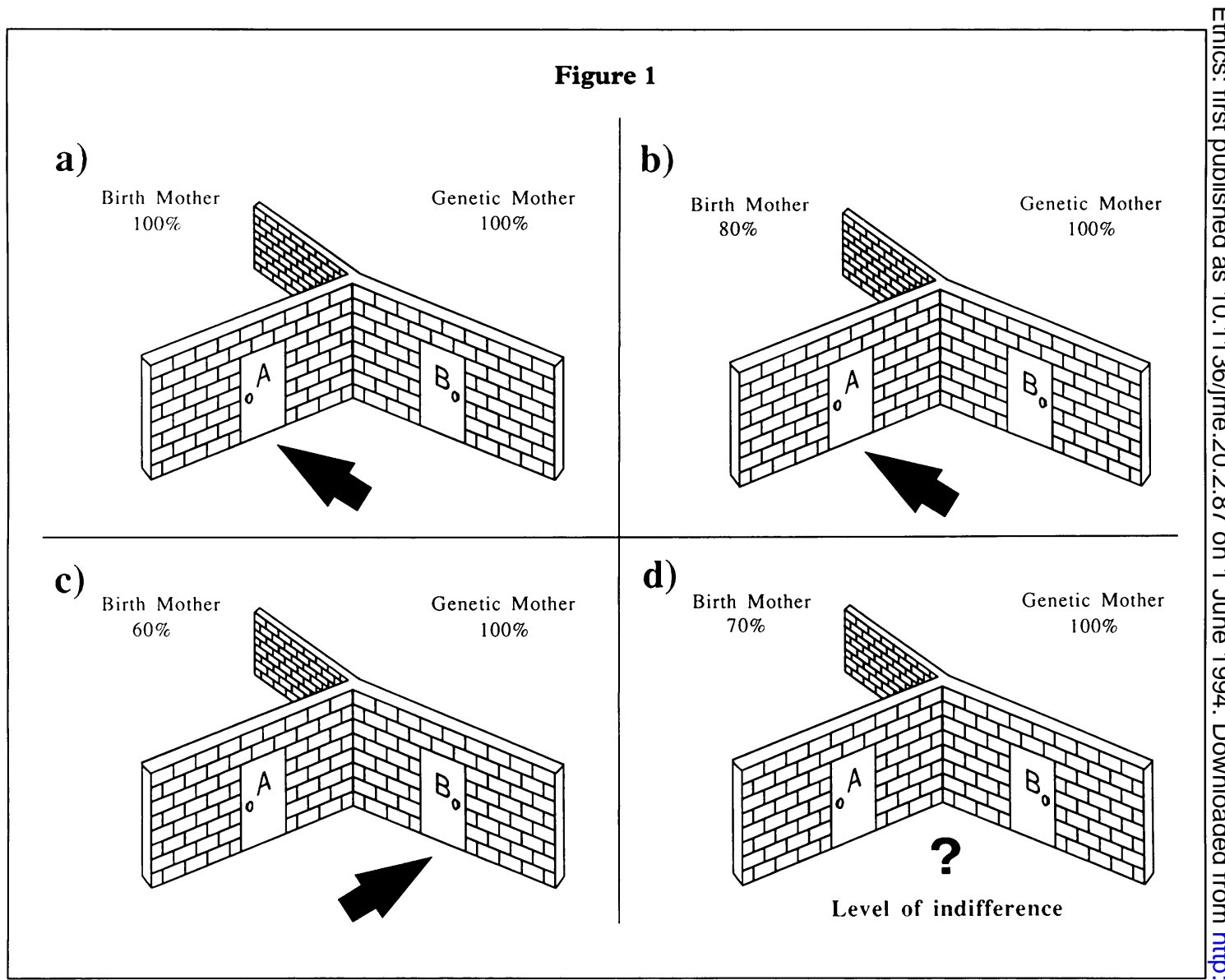

a) The choice between certain birth and genetic motherhood. The example subject prefers birth motherhood. b) The lottery at which she still prefers birth motherhood. c) The lottery at which she prefers genetic motherhood. d) The lottery at which she is indifferent between birth and genetic motherhood.

years and included both medical and non-medical workers and patients from the gynaecology and postnatal wards of a university hospital. The second sample consisted of 50 men aged between 19 and 38 years and again included doctors, medical students, paramedical staff and lay people visiting patients in the same hospital. Overall, $23 / 50$ women and $26 / 50$ men were non-medical.

Each person was interviewed privately. Women were asked to imagine that they were infertile and to make the following hypothetical choice. If they had only one pregnancy, would they prefer to be the genetic or the birth mother? They were told that in both cases, their partner's sperm would be used and that the chances of success were 100 per cent.

After eliciting her preference, the subject was asked at what chance (below 100 per cent) of having a baby by her preferred option, would she change her mind? We thus measured both the direction and strength of the original preference.

To aid understanding we asked subjects to imagine that the relevant choice outcomes lay behind two doors. The subject had to choose to enter one door and after each choice the chances were varied until a point of indifference was $ㅇ$ identified. For example, a subject might indicate $\rightarrow$ that she would prefer to be a birth mother (Figure 1a). When asked to choose between being a birth $N_{\sigma}$ mother with an 80 per cent chance of success and $N$ certain success as a genetic mother, she still opted to 0 be a birth mother (Figure 1b). However, when the $\omega$ birth mother success fell to 60 per cent, she preferred the genetic mother option (Figure 1c). She was indifferent between 70 per cent success as a birth mother and certain genetic motherhood ${ }^{+}$ (Figure 1d).

Men were asked the same questions except that $\stackrel{0}{\mathbb{D}}$ the choice was whether their wives or partners could $\frac{\rho}{\mathbb{Q}}$ become birth or genetic mothers. Men were asked to $\varrho$ assume that in either case, they would be the genetic father. We thus measured the direction and strength $\delta$ of preference for their partner's motherhood. The을 statistical significance of any differences in the responses of different groups of subjects was measured by the Mann Whitney test. 


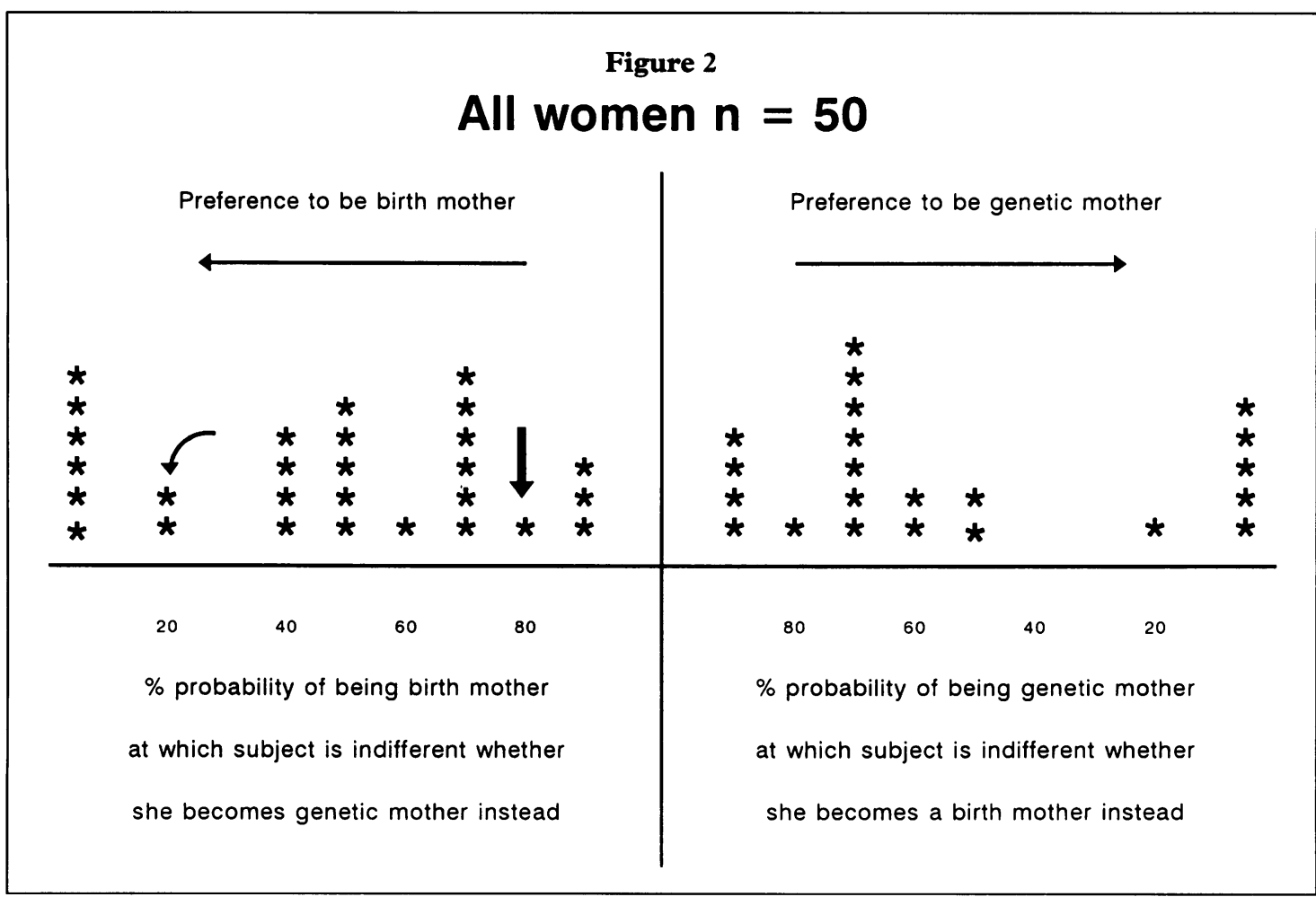

Plot of the direction and strength of preference for birth or genetic motherhood of a sample of 50 women (see text for arrowed cases).

\section{Figure 3}

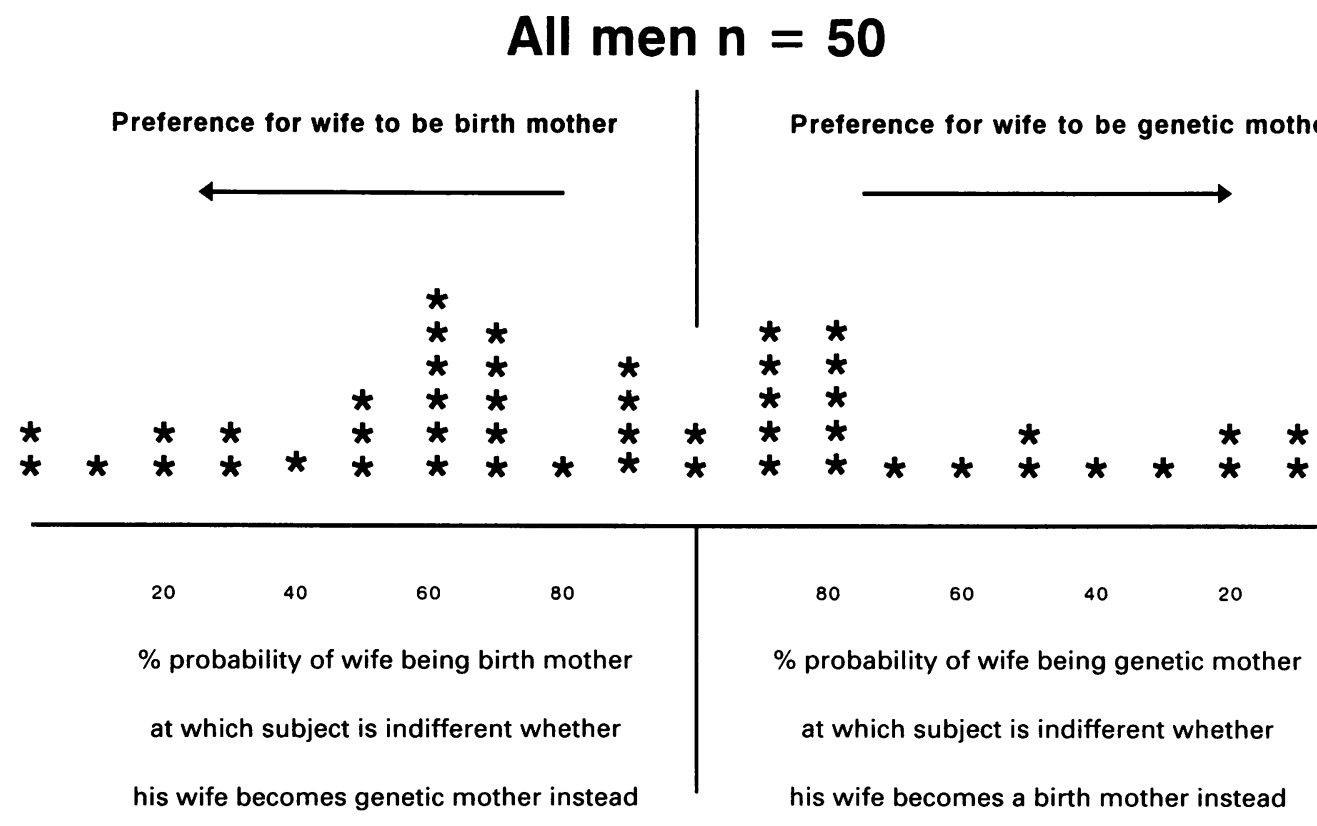




\section{Figure 4 \\ Men with children $n=16$}

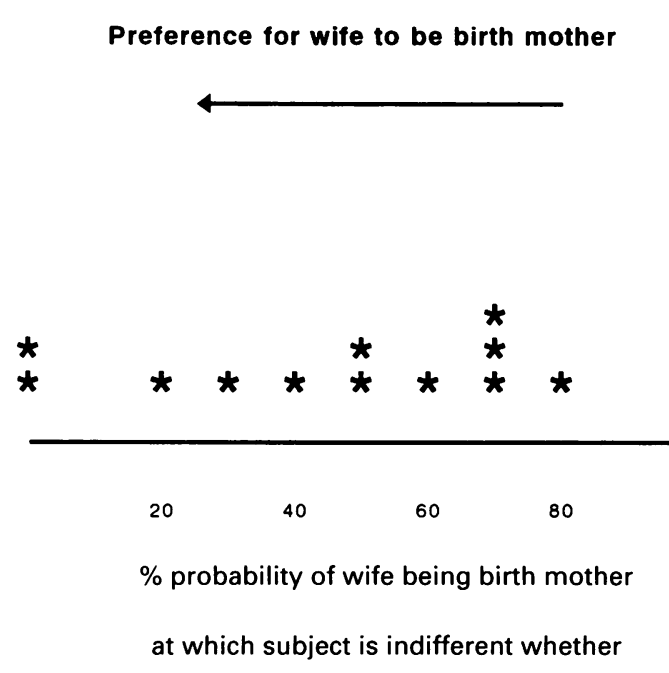

his wife becomes genetic mother instead
Preference for wife to be genetic mother

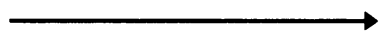

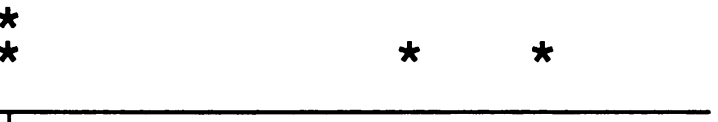

$\begin{array}{llll}80 & 60 & 40 & 20\end{array}$

$\%$ probability of wife being genetic mother

at which subject is indifferent whether

his wife becomes a birth mother instead

Plot of the direction and strength of preference of 16 men with children for their partners to be birth or genetic mothers.

\section{Results}

\section{WOMEN}

When asked to state a simple preference, 28 women took the birth mother option and 22 preferred to be a genetic mother. No woman was completely indifferent. The strength of preferences of the women are shown in Figure 2. Each star represents one woman. On the left are those who preferred to be the birth mother and on the right those who preferred to be the genetic mother. The scale indicates the success rate with the preferred option at which they changed their minds. For example, in one case, to the left of the midpoint (Figure 2 straight arrow), the woman preferred to be the birth mother but if the success rate of being a birth mother was reduced to 80 per cent, she was indifferent between that and the genetic option at 100 per cent success rate. She had a weak preference to be a birth mother.

In contrast, there were two women (Figure 2 curved arrow) who also preferred to be birth mothers but continued to choose this option until the success rate of birth motherhood fell to 20 per cent. They had a relatively strong preference to be birth mothers. Similarly, on the right of the graph are those women who showed a weak preference to be genetic mothers nearer the centre, and those with a stronger preference further to the right. There was a wide range of preferences and the degree of preference for the favoured option was often quite strong. For example, six women stated that they would prefer to be birth mothers even if the chance of having a child that way was less than 10 per cent and five women⿳亠丷厂二 would have preferred to be genetic mothers even if the chance of success for genetic motherhood was lessothan 10 per cent. The results were not affected by age, 3 . parity, religion or occupation.

MEN

The results for the 50 men overall are shown in Figure 3. The distribution of preferences was similar? to that of the women. Among the men, the results were again not affected by age, religion op occupation but the preference of those with and N without children was different (Figures 4 and 5) in that those with children were more likely to prefero their wives becoming birth mothers $(p=0.012)$.

\section{Discussion}

There has been considerable debate over the relative importance of birth and genetic motherhood, with strong feeling expressed on both sides: 'A surrogate mother feels the fetus move. The fetus and mothero react on each other. Therefore, whether she donateक her ovum or accepted a tenant embryo, she has actually given part of herself over and above any germ tissue' (6); 'If real priority is given to the birtlif mother as against the genetic mother, it is difficult to see how the idea that mothers and fathers have equal 


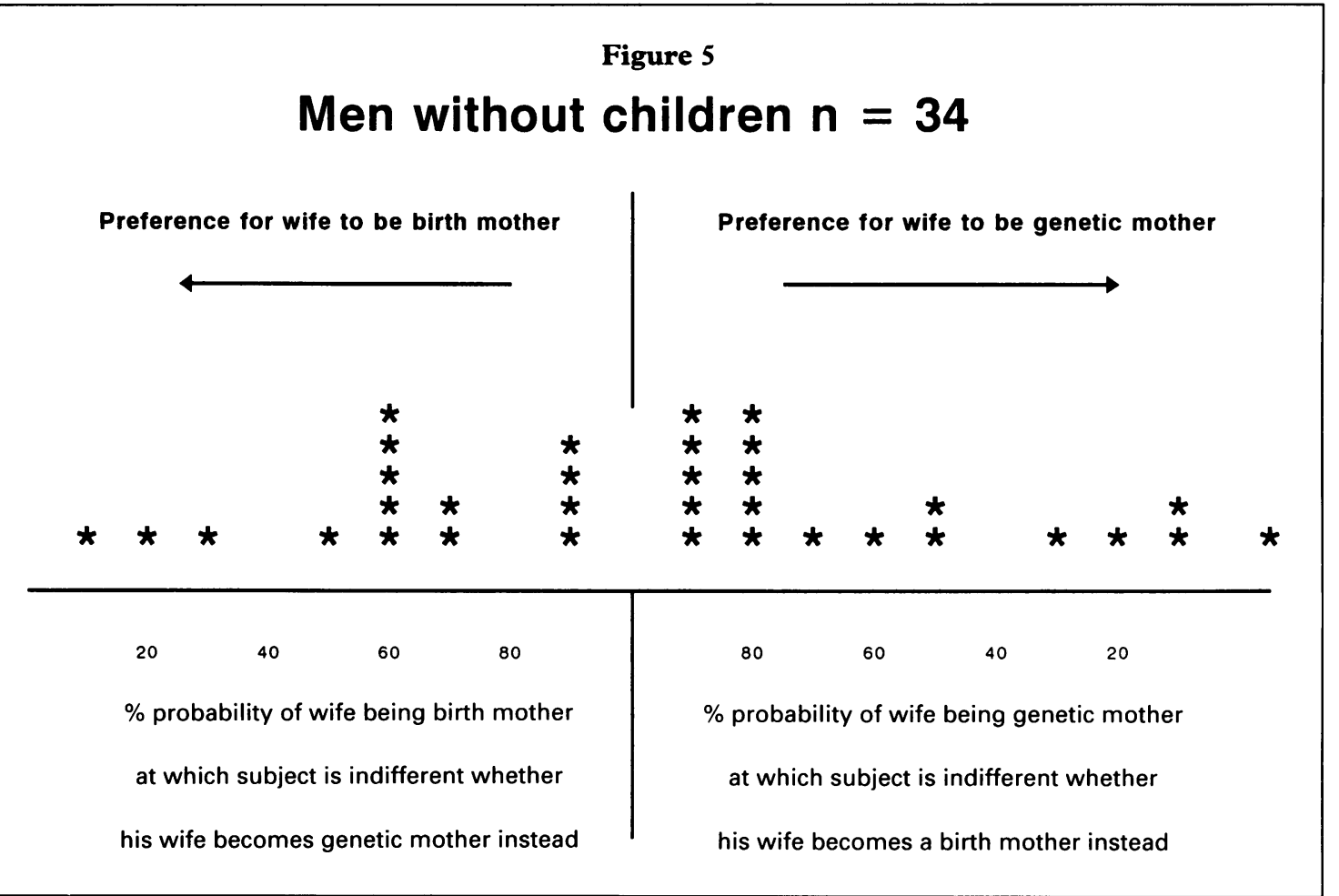

Plot of the direction and strength of preference of 34 men without children for their partners to be birth or genetic mothers.

parental rights can be maintained' (7). However, there has been little empirical research into people's attitudes.

The similar numbers expressing each preference, 28 birth and 22 genetic among women and 27 birth, 21 genetic and 2 neutral among men, indicate within the limitations of this study, that there is no consensus. The authors were mildly surprised that there was not a large majority for one or other option, although H M McNamara had expected the majority of women to prefer genetic motherhood and J G Thornton and I A Montague the opposite! All the authors had thought that men would prefer genetic motherhood for their partners.

The method used in this study for measuring strength of preferences has advantages over the alternatives, such as marking utilities on linear scales or expressing them in terms of 'willingness to pay money' or 'willingness to sacrifice years of life'. The clinical implications of utilities obtained by lottery are transparent to the subjects as they make their decisions and the results obtained are usually plausible (8). Similar empirical surveys of utility measures have been used to shed light on other reproductive choices, such as women's changing attitudes to pain relief before, during and after labour (9) and on the question of deciding between recipients of limited medical resources (10).
This study must be interpreted with caution since the sample may not be representative of the general population. If confirmed in a representative sample, it would demonstrate the wide range of people's views on this matter. Judges deciding custody cases should take such views into account. The difference in the views of men with and without children presumably reflects experience of their partner's pregnancies. Men without children find it difficult to imagine the experience of carrying a child in a way that women without children seem able to do.

The importance of deciding the relative importance of birth and genetic motherhood extends beyond the relatively rare cases of full surrogacy. Infertility due to ovarian failure, and high maternal genetic risk are increasingly treated by ovum donation. In these ovum donation cases it is the birth mother who is the commissioning mother and courts may then favour the birth mother's claims. For example, when the UK parliament considered this matter it was primarily considering ovum donation and it did take a different view. In the Human Fertilisation and Embryology Act (1990) it is stated: section 27, subsection 1: 'The meaning of mother; the woman who is carrying or has carried a child as a result of the placing in her of an embryo or of sperm and eggs, and no other woman, is to be treated as the mother of the child.' 
We believe that both the Californian courts and the drafters of the HFEA have failed to recognise the two important elements of maternity. A child with separate birth and genetic mothers has two mothers. It may be in its best interests that custody and perhaps also visiting rights are only given to one of them. If so such decisions should be made on relevant criteria, such as the best interests of the child or review of the contractual state of the parties. The problem cannot be sidestepped by arguing that only birth or genetic motherhood is significant since, as we have shown, people seem to regard them as approximately equally important.

f $G$ Thornton, MD, MRCOG, DTMoH, is Senior Lecturer/Honorary Consultant in Obstetrics and Gynaecology at the University of Leeds. H M McNamara, MB, DCh, DObs, is Registrar in Obstetrics and Gynaecology, Barrington's Hospital, George's Quay, Limerick, Ireland. I A Montague, MB, is Registrar in Obstetrics and Gynaecology at Bradford Royal Infirmary. All correspondence to Dr Thornton at the Institute of Epidemiology and Health Services Research, Leeds University.

\section{References}

(1) Anna J v Mark C, 286 Cal Rptr 369 (Ct App, 4th Dist, 1991).
(2) Johnson v Calvert, Cal Super Ct, Orange Co, Dep 11, No X633190 (Oct 22, 1990).

(3) Annas G J. Using genes to define motherhood - the

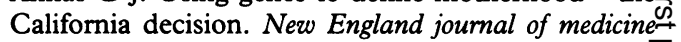
1992; 326: 417-420.

(4) American College of Obstetricians and Gyne-음 cologists, Committee on Ethics. Ethical issues in $\frac{\overline{5}}{\overrightarrow{5}}$

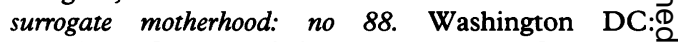
American College of Obstetricians and Gynecologists, 1990 Nov.

(5) Thornton J G, Lilford R J, Johnson N. Decision $\overrightarrow{0}$ analysis in Medicine. British medical journal 1992; 304: 1099-1103.

(6) Trusted J. Gifts of gametes. Fournal of applied philosophy 1986; 3: 123-126.

(7) Page E. Taking surrogacy seriously. In: Bromham, D R, Dalton M E and Jackson J C, eds. Philosophical ethics in reproductive medicine. Proceedings of the first International Conference of Philosophical Ethics in Reproductive Medicine (PERM). Manchester:음 Manchester University Press, 1990: 51-69.

(8) Weinstein MC, Findberg H V, eds. Clinical decision analysis. Philadelphia: W B Saunders, 1980.

(9) Christenzen-Szalanski J J J. Discount functions and ${ }^{\circledR}$ measurement of values. Women's decisions during $\vec{c}$ childbirth. Medical decision making 1984; 4:॰ 47-58.

(10) Lewis P A, Charny M. Which of two individuals to you treat when only their ages are different and you cannot treat both. Fournal of medical ethics 1989; $15: \overline{\mathrm{O}}$ 28-32.

\section{News and notes}

\section{Medical law journal launched}

Medical Law Monitor, a new journal, was launched in January with an introductory issue which summarises 'some of the most important developments in medical law in the last year'. The journal aims to inform readers as to significant case law, legislative and procedural changes and also to 'analyse the implications of these changes for the providers of healthcare'.

The journal will be published ten times a year by Monitor Press, Rectory Road, Great Waldingfield, Sudbury, Suffolk CO10 0TL. The editor is Julie Stone.
Continued from page 68

explained and where possible justified. What, for example, does the council mean by 'solidarity' and by 'equity'? These ethical terms are open to widely disparate interpretations.

Of course, had the council carried out such an exercise for the current report its conclusions may well have remained unchanged. However, it is the justification of conclusions in the light of the strongest available counterarguments that is at the heart of bioethics. From that perspective the Nuffield Council on Bioethics has not - in its first report - yet measured up to, let alone surpassed, the 'gold standard' of such reports provided by the US president's commission on bioethics over ten years ago.

\section{References}

(1) Nuffield Council on Bioethics. Genetic screening: $\frac{0}{\frac{1}{1}}$ ethical issues. London: Nuffield Council on Bioethics, 1993.

(2) See for example: president's commission for the study $\frac{0}{0}$ of ethical problems in medicine and biomedical and behavioural research. Making health care decisions: the ethical and legal implications of informed consent in the尺 patient-practitioner relationship (vols 1-3). Washingtono DC: President's Commission, 1982. And: president's commission for the study of ethical problems in medicine and biomedical and behavioural research. Splicing life: the social and ethical issues of genetico. engineering with human beings. Washington DC:? president's commission, 1982. 